\title{
LA INTRODUCCIÓN DE LA ESCRITURA Y LA SOCIEDAD INDÍGENA EN LA PAMPA ARGENTINA (SIGLO XIX) ${ }^{1}$
}

\section{Carlos Gabriel PERNA ${ }^{2}$}

\section{Resumen}

En el marco de un proceso histórico como la hispanización lingüística de los territorios indígenas pampeanos, nos proponemos detenernos en el análisis de algunos aspectos generales de la cultura que se ven afectados por la introducción de la escritura en una sociedad de cuño oral, en concreto, la circulación y el control de información y la conservación del conocimiento, como así también algunas consecuencias directas e indirectas en la organización socio-política de la sociedad receptora de dicha influencia. El estatus alcanzado por escribas y lenguaraces, así como la práctica archivística entre los indígenas ofrecen algunas claves para dar respuesta a estas cuestiones.

Palabras clave: Introducción de la escritura - oralidad - memoria - conocimiento - práctica archivística

\begin{abstract}
In the framework of a historical process such as the linguistic hispanisation of the pampean indigenous territories, we analyze some general aspects of the culture that are affected by the introduction of the scripture into an oral society, in particular, the movement and control of information and the conservation of knowledge, as well as some types of direct and indirect impact on the socio-political organization of the receiving society of such influence. The status achieved by escribas and lenguaraces, as well as the archival practice between the indigenous pampeans, offer some answers to these questions.
\end{abstract}

Keywords: Introduction of scripture - orality - memory - knowledge - archival practice

\section{Résumé}

Dans le cadre d'un processus historique comme l'hispanización linguistique des territoires indigènes de la pampa, nous nous proposons de nous arrêter dans l'analyse de quelques aspects généraux de la culture qui se trouvent affectés par l'introduction de l'écriture dans une société oral, en somme, la circulation et le contrôle d'information et la conservation de la connaissance,

\footnotetext{
1 El presente texto es versión ampliada y actualizada de un capítulo de mi tesis para alcanzar el grado académico de Magister Artium en Filología Románica y Filología del Alemán como Lengua Extranjera bajo el título: "Entornos de la comunicación. Indios y cristianos en la frontera argentina del siglo XIX“" (Heidelberg, 2010).

2 Doctorando de la Ruprecht-Karls-Universität Heidelberg (Seminario de Romanística). E-mail: carlosperna28@gmail.com.
}

Fecha de recepción del artículo: Enero 2013

Fecha de evaluación: Abril 2013 
comme j'ai aussi pris quelques conséquences directes et indirectes dans l'organisation politicosociale de la société réceptrice. Le statut social atteint par des escribas et les lenguaraces, ainsi que la pratique archivistique entre les indigènes de la pampa ils offrent quelques clés pour donner la réponse à ces questions.

Mots-clés: Introduction de l'écriture - oralidad - mémoire - connaissance - pratique archivistique

La publicación en las últimas décadas de documentos, especialmente de tipo epistolar, concernientes al período que sigue a la época de Rosas hasta 1880, tales como los publicados por Marcela Tamagnini $\left(1995,{ }^{2} 2010\right)$, la recopilación de "cartas mapuches" que hace Pávez Ojeda (2008), así como la interesante presentación de Guillermo Durán del archivo de Estanislao Zeballos (2006), entre otros, ofrecen una base de datos consistente para la creciente masa de tesis etnológicas e históricas que toman como objeto las relaciones interétnicas en dicho período; al mismo tiempo, estos documentos posibilitan la apertura de otras perspectivas de análisis de tipo lingüístico como la que queremos presentar en las siguientes páginas ${ }^{3}$.

Estos documentos no son solamente el testimonio del uso de variedades rurales y contactuales del castellano en los territorios pampeanos de las provincias de Córdoba, San Luis, La Pampa y Buenos Aires, ofreciendo en sí un reflejo más real que el que en más de una oportunidad se ha querido ver en el espejo de la literatura gauchesca, sino que también se puede pensar a los mismos como el preámbulo a la dominación efectiva de pueblos indígenas que habían mantenido hasta entonces una relativa independencia respecto a España en época de la colonia, y a los países del cono sur americano, tras el proceso de independencia del poder colonial. Desde una perspectiva etnolingüística nos interesa centrarnos en lo que se podría considerar como uno de los últimos capítulos decisivos en la hispanización lingüística ${ }^{4}$, hasta casi alcanzar las fronteras que posee hoy en día el territorio argentino. El avance sobre la Patagonia y el noreste del país terminarían de dibujar este mapa inaugurando variedades diatópicas como el español de la Patagonia. Al mismo tiempo y como proceso paralelo a la hispanización se produce una marginalización de la lengua mapuche en estas regiones.

En este ensayo nos parece esencial considerar los cambios que la escritura como práctica cultural en sus rasgos más generales o universales introduce en una sociedad que carece de la misma, cambios que afectan no sólo lo estrictamente cultural, como la circulación y el control de información y la conservación del conocimiento, sino que también tienen consecuencias directas e indirectas en la organización socio-política de la sociedad receptora de tal influencia. En este sentido, nuestra perspectiva se corresponde a lo que Eugenio Coseriu identifica como el objeto de la etnografía lingüística, es decir no "los cambios del lenguaje en cuanto motivados por cambios en la civilización y la cultura", que sería una tarea de la llamada etnolingüística, sino "los cambios en la cultura manifestada por el lenguaje" (Coseriu 1981:29).

\section{"Vías de extinción o reinvención"}

\footnotetext{
${ }^{3}$ La edición más completa corresponde a Marcela Tamagnini (1995, $\left.{ }^{2} 2010\right)$, la numeración que se indica en las citas corresponde sin embargo a la asignada en el catálogo del Archivo Histórico del Convento San Francisco Solano de Río Cuarto, en donde fueron recogidas por la autora; las cartas correspondientes a indígenas están publicadas además en Pávez Ojeda (2008). De inestimable valor también es la edición de las memorias del ex cautivo Santiago Avendaño (2004) por su conocimiento directo y prolongada estancia en la sociedad indígena. Gregorio-Cernadas (1998) ofrece un análisis de algunos problemas relativos a las fuentes históricas de la diplomacia indígena en la pampa.

${ }^{4}$ Para un planteo general y programático de las "corrientes de hispanización" lingüística en Hispanoamérica, véase Jens Lüdtke (2007). El concepto se basa en planteos históricos de Francisco Morales Padrón.
} 
La escritura introduce en la sociedad indígena no sólo un elemento cultural hasta ese momento desconocido o, al menos, irrelevante, sino también una especialización y división del trabajo que van de la mano con una jerarquización de los agentes que poseen la habilidad de la lectoescritura. Es decir, los factores que anteriormente determinaban la división social del trabajo, tales como género, edad, jerarquía social, etc., no pesan mayormente sobre este nuevo elemento, sino que, al contrario, la lecto-escritura introduce nuevas lógicas determinantes de la división del trabajo basadas en el conocimiento, es decir en este caso, en la posesión de una habilidad determinada, y se integra como elemento constitutivo de nuevas elites sociales ${ }^{5}$.

Por supuesto, la lecto-escritura no es el único ni el primer elemento que el contacto cultural introdujo en las sociedades indígenas pampas y araucanas de los territorios de la pampa argentina. Las sociedades indígenas independientes habían sido capaces en el pasado de incorporar otros elementos nuevos de la cultura material española obteniendo una ventaja de los mismos, como es el caso de la introducción del caballo:

With the coming of Spaniards, Pampas and Patagonians became mounted hunters of cattle and horses, their societies transformed in ways that made them, like the Araucanians, more formidable warriors. Horses increased their range, facilitated their consolidation from small family groups into larger bands and tribes, and made it possible for their leaders to command larger forces than ever before. Horses, cattle, and sheep provided a steady supply of protein, and an enriched diet probably contributed to an increase of population among these Natives who previously hunted guanacos and ostrichlike rheas on foot. ${ }^{6}$

Aunque el caballo había inducido una mayor homogeneidad cultural y centralización política, en especial en tiempos de guerra cuando la necesidad de unidad confería a los caciques araucanos mayor poder de coerción, la estructura demográfica de las tribus pampeanas y araucanas seguía siendo de gran dispersión. El clima semiárido del territorio de la pampa seca, por ejemplo, ponía una barrera natural a una mayor densidad demográfica obligando a mantener cierta distancia entre una toldería y la otra para disponer de las pasturas suficientes para el ganado, la base de su economía. Es decir, la cría del caballo no solamente no modificó mayormente este orden demográfico de relativa dispersión, sino que, al contrario, en ocasiones lo intensificó. David Weber llama a esta estructura social "residential decentralization and political centralization". Una gran diferencia consistía en que los caciques poseían ahora poder para reunir una mayor cantidad de guerreros para la defensa en caso de un ataque español, o para organizar un "malón" a territorios cristianos con el fin de obtener ganado. En tiempos de paz, sin embargo, su autoridad seguía siendo limitada, y la sociedad seguía estando organizada sobre todo en núcleos tribales y familiares dispersos, ya que ahora esta "cultura ecuestre" dependía de la existencia de agua y pasturas suficientes para el ganado. Tal organización social no sólo impedía a los españoles localizar un centro definido contra el cual dirigir sus

\footnotetext{
5 En qué medida la incorporación de un elemento nuevo como la escritura modifica la estructura social anterior y se integra en ella es asunto de discusión teórica. Vease junto a los textos de Goody (1990) y Goody y Watts (1987), también Messick (1983), que plantea el caso de una sociedad donde la lengua de la escritura es la misma que la hablada y no una lengua extranjera.

${ }^{6}$ Apud David Weber (2005: 64). Traducción: "Con la llegada de los españoles, los indios pampas y patagones devinieron cazadores montados de ganado vacuno y caballos salvajes, sus sociedades se vieron transformadas de tal modo que se hicieron, como los araucanos, guerreros formidables. Los caballos aumentaron su rango, facilitaron su consolidación de pequeños grupos familiares en bandas y tribus más grandes, y esto hizo posible para sus líderes mandar sobre mayores fuerzas que nunca antes. El caballo, el ganado vacuno y la oveja proporcionaron un suministro estable de proteínas, y esta dieta enriquecida probablemente contribuyó a un aumento de la población entre estos habitantes del país que antes cazaban a pie guanacos y ñandúes”. En los siguientes párrafos seguimos también el análisis de Weber, en especial sus planteamientos sobre la llamada "horse culture" o también "horse complex". Véase en particular sobre las culturas pampas y araucanas las págs. 54, 79, 81. También sobre el tema se puede consultar Carlos Martínez Sarasola 1992: 125ss. y 236-237.
} 
operaciones militares o, simplemente, con el cual negociar de manera directa, sino también hacía a los grupos indígenas menos susceptibles de padecer los virus y enfermedades que diezmaron las grandes sociedades indígenas sedentarias de las altiplanicies americanas. El ganado equino, bovino y ovino introduciría además profundas modificaciones en la organización económica de la sociedad indígena, reemplazando "su original patrón agricultor y pastor por el de cazador" (Martínez Sarasola 1992: 132). El agotamiento del ganado cimarrón y las necesidades de expansión territorial de los productores agropecuarios de la pampa conduciría en los siglos XVIII y XIX a una creciente competencia por los recursos naturales y, consecuentemente, a un aumento de la conflictividad entre cristianos e indígenas en los territorios pampeanos.

Elementos como el caballo o la escritura representan reformas sociales y culturales tan radicales que, en concepto de David Weber, colocan a una cultura frente a una "way of extinction or reinvention" (2005: 54). La introducción del caballo provocó en este sentido una auténtica "reinvención" de las sociedades araucanas y pampas, en tanto la cultura indígena supo tornar a su favor este elemento nuevo aprovechando sus ventajas y fortaleciendo su independencia. Los cambios que introdujo la escritura son, sin embargo, de otro tipo, y de este asunto nos proponemos ocuparnos en las siguientes páginas.

Julio Vezub (2006: 305) explica las reformas sociales que la escritura trajo aparejadas en la sociedad indígena en los siguientes términos:

La disponibilidad de capital humano capaz de ejercitar la lecto-escritura estaba en relación directa con la cristalización del poder. La política, el comercio y el control de la información compusieron un tríptico en las sociedades de frontera del siglo XIX. La práctica de la escritura ordenó y disciplinó a las elites de los toldos, e introdujo lógicas estatales. Desde la perspectiva de los caciques, los amanuenses fueron indispensables para la gestión exitosa de las raciones, y para cualquier otro entendimiento político o económico, ya fuera con indígenas o con cristianos.

Esta habilidad era desempeñada por los llamados "lenguaraces". Dadas las diferencias idiomáticas entre unos y otros, los lenguaraces eran individuos bilingües que actuaban como intermediarios entre las dos etnias, sea para la comunicación oral, sea para la escrita. Hacia el interior de la sociedad indígena, contar con intérpretes y lenguaraces como sus "secretarios" permitió a los caciques, además de asegurar su situación como "nodo informático" (Martha Bechis 2008, 292ss.), monopolizar las relaciones con los cristianos y, en consecuencia, controlar también los beneficios materiales, políticos y estratégicos que dichas relaciones devengaran. Las "raciones" y "regalos" que los cristianos entregaban a los indígenas, llegaban a éstos, pues, por intermedio de sus caciques, quienes de este modo fortalecían su posición de poder en la sociedad indígena.

La cultura araucana, a diferencia de la española, no se basaba en la acumulación de bienes y valores, sino en una circulación diferente de bienes y mercaderías que creaban vínculos particulares entre dador y receptor de los mismos. El "regalo" jugaba un rol cultural de consideración:

The bestowing of gifts, which increased the status of the giver, often established an alliance or a familial relationship -a "fictive Kinship", and the receipt of gifts came with the obligation of reciprocity, even among "kin".

El cacique que era "generoso" distribuyendo entre sus subordinados en la tribu se aseguraba la "gratitud" de sus indios, creando así un vínculo de reciprocidad que obligaba al receptor a devolver este regalo con que se lo honraba, fuera en forma de otros objetos materiales, en

\footnotetext{
${ }^{7}$ David Weber (2005: 191). Traducción: "La concesión de regalos, que aumentaba el estatus del dador, a menudo establecía una alianza o una relación familiar -un 'parentesco ficticio'-, y el recibo de regalos venía con la obligación de reciprocidad, aún entre 'familiares" ".
} 
alguna forma de homenaje que expresara gratitud, o quedando simplemente obligado a prestar asistencia militar al cacique cuando éste lo requiriese. Es en este entorno cultural, pues, que debe entenderse la palabra racionar en boca del cacique Mariano Rosas:

Mi padre Mi solisitud ante el Presidente es pidiendole me aumente mil lleguas mas; entonces podre reunir todos los yndios q $\mathrm{q}^{\mathrm{e}}$ estan bibiendo por los Campos y racionarlos (D 412)

También le pido al General quinientas lleguas por lo pronto para darles a estos yndios gauchos y desirles que esto es del trabago que estoy asiendo para que bibamos en paz y suplico a Vd. que (...) me las den por que de otro modo como podre sugetar estos gauchos (D 219)

Disponiendo de mayores raciones, el cacique puede "sujetar a los indios gauchos", y de esta forma fortalecer su posición de intermediario e interlocutor válido en las relaciones con los cristianos, quitando legitimidad al mismo tiempo a otros indígenas que no se someten a su autoridad. Desde la perspectiva inversa, es un motivo para negociar con los cristianos un aumento de las raciones: a mayores raciones, mayor control sobre mayor cantidad de indígenas. Una denominación reservada a uno y otro lado de la frontera para los individuos renuentes a la autoridad es, pues, la de "gaucho". Lucio V. Mansilla menciona lo que los indios llaman indio gaucho, sugiriendo con este comentario metalingüístico que la denominación no era usual para él o para sus lectores en Buenos Aires, sino típica de otro entorno regional (Coseriu 1955/56, 1967).

A la orilla de ellos [los montes del cuero] vivia el indio Blanco, que no es ni cacique, ni capitanejo, sino lo que los indios llaman indio gaucho. Es decir, un indio sin ley ni sujecion á nadie, á ningún cacique mayor, ni menos á ningún capitanejo; que campea por sus respetos; que es aliado unas veces de los otros, otras enemigo; que unas veces anda á monte, que otras se arrima á la toldería de un cacique; que unas anda por los campos maloqueando, invadiendo, meses enteros seguidos; otras por Chile comerciando, como ha sucedido últimamente. (Cap. XI)

Nótese sin embargo que la designación indio gaucho no difiere en su sentido de la otorgada por los sacerdotes misioneros en una de las cartas, que adoptan la designación "indio gaucho" en tanto individuo que no se somete a la autoridad del cacique:

Mariano con sus cartas anatemiza a los Yndios gauchos, pero entre tanto nada les hace. (D 483)

La misma designación con igual sentido se emplea también en el texto del Tratado de Paz (D 259), esta vez con el calificativo adicional de ladrones. En el Acuerdo, el gobierno se compromete por su parte a prestar su apoyo a los dos caciques para que logren su control y sumisión, quitándole sus bienes y entregándolos a los Indios pobres y honrados que responden a su autoridad:

Mariano y Baigorria se obligan a perseguir a los Indios Gauchos ladrones quitándoles sus bienes y repartiéndolos a los Indios pobres y honrados que observan con fidelidad estos tratados de Paz y al efecto el Gobierno Nacional les prestará todo su apoyo.

Por supuesto, como hemos visto más arriba los caciques no piensan en "perseguir", sino que siguen sus propias estrategias de persuasión mediante las "raciones" para lograr la subordinación de indígenas que engrosen su tribu, o para tejer alianzas con caciques de otras. Los ejemplos muestran que esta no es una designación exclusivamente propia de los indios, como afirmara Lucio V. Mansilla, sino que era empleada con similar sentido por indígenas y cristianos en esta comunicación de frontera ${ }^{8}$. El comentario de Mansilla debe ser interpretado,

\footnotetext{
${ }^{8}$ Una construcción discursiva similar a „indios gauchos ladrones“ / ,indios pobres honrados“ se da en el texto del Tratado entre "desertores y criminales que se refugian en Tierra Adentro" y "cristianos refugiados en Tierra Adentro", siendo la sumisión y sometimiento a la autoridad la delgada línea
} 
entonces, como una explicación necesaria para un lector de Buenos Aires, no como una diferencia designativa entre indígenas y cristianos dentro de esta frontera.

La entrega de "regalos" acordes a la jerarquía de quien los recibía, cumplía además otras funciones simbólicas cimentando el carácter "personal" de la relación entre dador y receptor del regalo. Las relaciones personales tenían una configuración distinta en la sociedad indígena que en la cristiana. Silvia Ratto (2007) menciona que de los más de veinte años de gobierno de Juan Manuel de Rosas, época de predominio del llamado "Negocio Pacífico" con las parcialidades indígenas, en la que además se tejió y se mantuvo "una complicada y extensa red de relaciones" de cierta estabilidad hasta su caída en 1852, no quedan casi tratados o acuerdos de paz u otro tipo para regular las relaciones entre blancos e indios. A partir de esa fecha, la firma de tratados se torna cada vez más frecuente acompañando los vaivenes de la vida institucional de la República Argentina por una parte, así como los cambios de las autoridades militares de frontera, y las modificaciones de la autoridad entre los indígenas por fallecimiento de un cacique por otra, como se puede apreciar en una carta de Epumer Rosas (D 769) y otra de Namuncurá (D 832) dirigidas al padre misionero Donati para gestionar su intermediación y presentarse como nuevos interlocutores. La realidad es que hasta 1853 no se conservaron tales documentos porque sencillamente casi no los hubo'. Tal carencia fue interpretada por algunos historiadores como otra "astucia" del gobernador bonaerense, que eludía así atarse a compromisos escritos (Pávez Ojeda 2008: 57). Rosas, estanciero de frontera crecido en el contacto directo con las tribus indígenas y profundo conocedor de sus culturas ${ }^{10}$, sabía que no precisaba de tratados escritos. Los indígenas depositaban mayor confianza en las relaciones interpersonales y en la palabra dada que en un texto escrito en una lengua, además, que no era la propia:

La explicación se encuentra en el conocimiento que el gobernador tenía sobre las prácticas diplomáticas de estos grupos indígenas, basadas en una tradición oral y ágrafa en donde valía mucho más la palabra empeñada que un papel escrito en una lengua desconocida. De ahí que Rosas hiciera mayor hincapié en mantener largos parlamentos con los indígenas donde se repetían varias veces los puntos que se buscaba acordar, adoptando bastante fielmente las prácticas diplomáticas indígenas. (Ratto 2007: 103s.)

Los acuerdos más estables y duraderos en la frontera se basaron, por cierto, en relaciones personales de amistad, compadrazgo, etc., y el simple cambio de un jefe de frontera que había sido interlocutor de confianza durante largo tiempo, alcanzaba para dejar practicamente en la nada años de negociaciones; por ello también la preocupación permanente que se manifiesta en el relato de Mansilla y en las cartas de los misioneros y militares por construir con rasgos personales una entidad abstracta como el Gobierno que garantice la continuidad de lo acordado más allá de los cambios en el personal que lo representa:

Debes ser siempre leal y buen amigo del Gobierno, tener confianza en él y servirle bien, porque él recompensa á todos los que se conducen bien con él. (Ministro Martín de Gainza D 309)

La caída de Rosas y esfuerzos por definir el estado nacional que siguen a la constitución

discursiva que separa a una y otra categoría, categorías que, en otro universo de discurso, eran pasibles además de convertirse en auténticas figuras jurídicas. El destino que esperaba a muchos de los "refugiados" que regresaban a la civilización puede leerse en el D 451.

${ }^{9}$ Para una historia de las relaciones entre indios y cristianos y de los tratados firmados desde la época de la colonia, y no sólo en este período, véase A. Levaggi 2000.

${ }^{10}$ Una obra que practicamente no ha encontrado lugar ni en la historia de la lengua ni en la historia de la literatura en Argentina es, curiosamente, la Gramática y diccionario de la lengua pampa, de Juan Manuel de Rosas [1825], uno de los primeros esfuerzos por incorporar sistemáticamente a los conocimientos de la cultura criolla la lengua, cultura y territorio de los indígenas de la pampa. La obra es incluso ignorada en trabajos específicos sobre el tema como el de Irma Bernal (1997). Un análisis de este texto en una perspectiva lexicográfica se encuentra en Laura Kornfeld e Inés Kuguel (1995). 
nacional sancionada en 1853 acompañarán un quiebre en el tipo de relación que había tenido lugar hasta entonces con las sociedades indígenas, conocida como el "negocio pacífico". La comunicación diplomática epistolar, ya frecuente entonces, se intensificará aún más, al igual que los tratados de paz se multiplicarán.

\section{Algunos rasgos de la escritura}

Para ofrecer un principio de definición, diremos que, a diferencia de la oralidad, la escritura se desarrolla como un sistema de comunicación autónomo y emancipado del contacto directo; que además, gracias a la independización del campo mostrativo (al. Zeigfeld en Karl Bühler 1965), permite construcciones conceptuales abstractas organizables en categorías. Mediante la escritura el poseedor de un conocimiento, pongamos por caso la fundición de metales, logra transmitirlo prescindiendo del contacto en una situación concreta, valiéndose de conceptos escritos. Los conceptos se organizan en sistemas de conocimiento que les dan un lugar y un valor dentro de las jerarquías de saberes de una sociedad. La organización jerárquica de los conocimientos se realiza tanto en un tratado de metalurgia o en un diccionario, como en el orden temático de una biblioteca o las materias de la currícula escolar. Los modos de circular y organizarse que permite la escritura se contraponen por cierto a los modos de circulación y organización del conocimiento de una sociedad de tradición oral ${ }^{11}$, en tanto la escritura propicia, por principio, la transmisión de experiencias prescindiendo de la presencia directa, como es el caso del conocimiento que se transmite en el ejercicio de un oficio cotidiano: la práctica de la metalurgia en el taller de un herrero, con sus expertos, aprendices, y todo un abanico de relaciones propias de variado tipo (colegas, clientes, proveedores, etc.).

La constitución de diversos universos de discurso (Coseriu 1955/56, Álvarez Castro 2006) es una consecuencia directa de la jerarquización de los saberes. Si un texto refiere al mundo real mediante un lenguaje cotidiano o siguiendo pautas científicas, si remite a un mundo posible o ficticio, o bien si actúa modalmente sobre el actuar en el mundo, es ésta una intencionalidad básica que subyace a cada texto y hace explícito al receptor el modo de procesar y organizar la información que el texto transmite: un texto que informa ateniéndose con rigor científico sobre la fundición del hierro, un relato imaginario con animales que hablan o un tratado de moral y buenas costumbres encontrarán en una biblioteca estantes diferentes para ser guardados.

Cuando hablamos de la escritura lo hacemos en un sentido amplio, considerando también otras formas de representación gráfica, tal el caso de la numeración, y los géneros de que forman parte. La confección de remitos y recibos comerciales, entra también en esta categoria porque ofrece la posibilidad de comparar lo escrito con la realidad o con lo escrito en otros textos:

Y tambien le suplico $\mathrm{q}^{\mathrm{e}}$ bea con rrespeto alas lleguas $\mathrm{q}^{\mathrm{e}}$ me anmandado ultimamente mi comisionado me dise quememandaban tres cientas pero que él no las arrecibido por cuenta y qué al dia ciguiente cuando las acontado anotado una gran falta, y luego que en el oficio que medirije el $\mathrm{S}^{\text {or. }}$ Comte. no me asina el numero de lleguas queme rremite en esto me ase comosea malicia, ho almenos q $\mathrm{e}^{\mathrm{e}}$ haiga equibocacion. (D 284)

Consciente de esta posibilidad que ofrece la escritura, Cafulcurá solicita a Mitre en una carta detallar por escrito lo que se envía para evitar robos, esta vez de sus propios enviados:

Yo no sé si estos dos usaron de picardia conmigo; se perdieron siete prendas de plata, freno, espada, estribo, chapeado, el pretal, el rebenque, fiador; se perdieron siete mantas, un poncho de

\footnotetext{
${ }^{11}$ Según Jack Goody e Ian Watt (1981: 47), junto a los elementos de la cultura material y los recursos materiales de una sociedad que se heredan, deben considerarse los modelos de acción generales - que se aprenden no sólo mediante la comunicación lingüística sino también mediante imitación-, las representaciones espacio-temporales de una cultura, así como sus aspiraciones y objetivos generales como comunidad, es decir, todo aquello que forma parte de la "concepción de mundo" de una sociedad.
} 
paño. Todas estas prendas que le digo de ellas, no recibí ninguna cosa. De esto sin duda, éstos se quedarían con todo. Cuando me mande mándeme por escrito lo que me manda. (Pávez Ojeda 2008: 378)

Resumiendo, se pueden suponer cuatro propiedades generales y universales de la escritura interdependientes entre sí:

- permanencia por su soporte material,

- objetividad,

- prescindibilidad del contacto directo y,

- comparabilidad con la realidad o con otros textos.

Estas propiedades tienen consecuencias prácticas inmediatas y directas que hemos intentado describir a grandes rasgos en este punto, y consecuencias mediatas que calan en la organización interna de una cultura, de las que nos ocuparemos en lo que sigue.

\section{Escritura y memoria}

Santiago Avendaño (2004: 157s.), cautivado de niño, fue admitido en la toldería de Caniú, un subordinado del gran cacique Pichuiñ, y tratado allí como si fuera un hijo. Consciente de sus condiciones el cacique le prometía un notorio futuro en la sociedad indígena:

Caniu-Calquín me estimaba y me trataba bien. Me hablaba de la esperanza que ponía en mí. En momentos de familiaridad mi padre adoptivo me decía no una sola vez:

- Hijo, vos vas a ser un gran hombre. Cuando seas maduro, nos vas a tener en la palma de tu mano. Nuestra suerte va a depender de vos. Sabés hablar en la lengua nuestra como si fueras indio y hablás con el papel como si hablaras con alguien. Vé lo que fue Zúñiga en Chile. Ve lo que es Baigorria aquí, quien, aunque causa risa el oirlo hablar, vale mucho para nosotros y consigue las mejores relaciones entre indios y cristianos.

Pero Avendaño no era estimado en las tolderías solamente por hablar ambas lenguas y ser el cristianito que sabía hablar con el papel (Salomón Tarquini 2006). Según se trasluce de su testimonio, los indígenas se admiraban también al oirlo rezar sus plegarias, aún cuando éstas fueran en castellano y no entendieran su contenido:

Mi padre adoptivo jamás me impidió la devoción, ni ninguno de la casa hizo burla de mis oraciones; por el contrario, se me pedía que rezase en voz alta, a fin de oirme. Aunque no comprendían nada, me tenían siempre admiración al contemplar mi memoria. (Avendaño 2004: 161)

En concepto del cacique, Santiago Avendaño destacaba entre los demás cautivos por su despejo, memoria y claridad en la expresión (2004: 163). Como en toda cultura oral, la memoria desempeña un papel relevante que difiere notoriamente del de las culturas organizadas en torno a la escritura. Cuando consideramos las formas comunicativas en la sociedad araucana, vale la pena destacar que, según lo presenta Mansilla, lo que puede parecer un simple floreo retórico, una redundancia inútil, si se varía la perspectiva etnolingüística tiene en realidad en esta cultura de cuño oral una función claramente mnemotécnica:

Pues bien, convertir una razón en dos, en cuatro o más razones, quiere decir, dar vuelta la frase por activa y por pasiva, poner lo de atrás adelante, lo del medio al principio, o al fin; en dos palabras, dar vuelta la frase de todos lados.

El mérito del interlocutor en parlamento, su habilidad, su talento, consiste en el mayor número de veces que da vuelta cada una de sus frases o razones; ya sea valiéndose de los mismos vocablos o 
de otros; sin alterar el sentido claro y preciso de aquéllas.

No deja de ser oportuno aquí volver sobre la famosa fórmula de Walter Ong: "se sabe lo que se puede recordar". En este mismo sentido también se puede poner en relación la lección que Juan Manuel de Rosas había aprendido en su trato frecuente con los indios: lo que debe ser recordado precisa sobre todo de la repetición para quedar fijado en la memoria. La ecuación de repetir una misma frase variando la disposición sintáctica (por activa y por pasiva, poner lo de atrás adelante, lo del medio al principio, o al fin), pero también valiéndose de "otros vocablos", como sinónimos, antónimos, etc., aunque sin alterar el sentido, está precisamente en la base de lo que se conoce como tradición oral. También se podría agregar aquí elementos a nivel fónico como la rima, asonancias, etc. que son característicos de la poesía épica popular en la antigüedad y el medioevo. En la descripción de Mansilla se puede apreciar también que la cantidad de variaciones sólo está limitada por la habilidad del orador. En efecto, todo acto lingüístico no sólo reproduce formas conocidas, sino que está abierto a la creación y la innovación.

Más allá, en la memoria humana se excluye la conservación absoluta, es decir, la posibilidad de recordar "todo", como le ocurre al personaje borgeano del cuento "Funes, el memorioso". La memoria humana debe seleccionar lo recordable y fijarlo mediante repetición para que no se mezcle y pierda junto con todo aquello que se considera superfluo. Resulta también interesante en la descripción de Mansilla el hecho de que la sociedad indígena otorgara valor a los individuos capaces de variar las frases el mayor número de veces. En efecto, "lenguaraz" era también un sinónimo de "buen orador", y la sociedad indígena independiente de las pampas y de Chile reservaba a los individuos con esta capacidad un lugar de preeminencia en la misma. De un cacique, por ejemplo, eran esperables dotes oratorias. Dotes que podían llegar a ser, además, un atributo central de su poder. Silvia Ratto cuenta respecto a los caciques pampas, Catriel y Cachul, de la defensa que Rosas hiciera de la necesidad de cuidar la relación amistosa con Cachul, aún cuando su apoyo militar era mínimo comparado con el primer cacique:

Cachul no es hombre de pelea, sino de política y así es que yo jamás lo he ocupado en dicha pelea por el contrario siempre he cuidado de un modo indirecto que no marche a ella, porque sabía que no había de hacer sino barros. Mas este mismo hombre flojo en la pelea es muy valiente en los consejos de la política sabiéndolo conducir; es entonces muy útil y de mucho acierto en sus discursos. Y de aquí mismo se deduce la razón para creer que si se le desagrada y él se propone enrredar con su astucia en el manejo de la política puede hacer un mal inmenso. ${ }^{12}$

Según Jan Assmann ${ }^{13}$, se puede distinguir dos formas de la memoria colectiva: la memoria comunicativa y la memoria cultural. Ambos tipos de memoria hacen un uso distinto del pasado. La memoria comunicativa remite al pasado inmediato, con una extensión que no sobrepasa las tres o cuatro generaciones, es decir, no más de 80-100 años, y tiene la forma de recuerdos vivenciales o biográficos; su desenvolvimiento se realiza en situaciones comunicativas cotidianas que no precisan de un especialista, sino que todo miembro de una comunidad, independientemente de que por su edad cuente con mayor o menor experiencia y recuerdos, participa de su estructura.

La participación en la memoria cultural, en cambio, no es difusa y general como la memoria comunicativa, sino diferenciada; así como es objeto de una comunicación ceremonial y no cotidiana. La memoria cultural tiene como función hacer presente un pasado remoto y fundante de tipo mítico que está en la base de las construcciones identitarias de una comunidad.

\begin{tabular}{|c|c|c|}
\hline & Memoria comunicativa & Memoria cultural \\
\hline Contenido & $\begin{array}{l}\text { Experiencias individuales de tipo } \\
\text { biográfico }\end{array}$ & $\begin{array}{l}\text { Relatos míticos sobre los orígenes en un } \\
\text { pasado absoluto }\end{array}$ \\
\hline Formas & Informal, desarrollo espontáneo & Alto grado de formalidad en ocasiones \\
\hline
\end{tabular}

\footnotetext{
${ }^{12}$ Carta del 13 de octubre de 1836. Cit. en Ratto 2007: 150s. Destacado en el original.

${ }^{13}$ Jan Assmann 2005: 48ss. Nuestra traducción del gráfico.
} 


\begin{tabular}{|c|c|c|}
\hline & mediante interacción cotidiana & festivas y ceremoniales \\
\hline Medios & $\begin{array}{l}\text { Recuerdos vivos en memorias orgánicas, } \\
\text { experiencias propias y "de oídas" }\end{array}$ & $\begin{array}{l}\text { Objetivaciones firmes, codificación } \\
\text { simbólica tradicional en palabras, } \\
\text { imágenes, danzas, etc. }\end{array}$ \\
\hline $\begin{array}{l}\text { Estructura } \\
\text { temporal }\end{array}$ & $\begin{array}{l}80-100 \text { años ( } 3-4 \text { generaciones). } \\
\text { Horizonte temporal se desplaza con los } \\
\text { cambios generacionales }\end{array}$ & Pasado absoluto de un tiempo mítico \\
\hline $\begin{array}{l}\text { Agentes } \\
\text { portadores }\end{array}$ & $\begin{array}{l}\text { No específico, agentes contemporáneos } \\
\text { de una comunidad }\end{array}$ & $\begin{array}{l}\text { Agentes especializados (ancianos, sabios, } \\
\text { sacerdotes, chamanes) }\end{array}$ \\
\hline
\end{tabular}

Santiago Avendaño (2004: 77), criado de niño entre los ranqueles, es consciente de estas diferencias entre la memoria comunicativa y la cultural y describe el papel desempeñado por los ancianos como archivos vivos, es decir, como agentes especializados en la conservación y transmisión de la memoria cultural en la sociedad de los Ranqueles en los siguientes términos:

Yo no pienso así porque lo que afirmo lo he palpado personalmente. $\mathrm{Y}$ he recogido entre los indios cuanto refiero de años atrás; y lo oí de aquellos indios que eran encargados de transmitir a los de la época los sucesos tal como se han desarrollado. Allí no había nada dudoso, a pesar de no tener los indios escritura por la que pudieran conservar perpetuamente la historia del pasado, de la antigüedad. Esos encargados eran los ancianos, archivos vivos, que tienen la responsabilidad ante Dios y los hombres de transmitir a su posteridad todo cuanto han oído de sus abuelos y de sus progenitores, tanto lo referente a sus glorias, como sus desgracias. Ningún indio que llega al uso de razón ignora los sucesos del pasado, porque están con sus maestros, que se lo enseñan. Y la palabra de un viejo, entre los indios, es palabra de Dios para su pueblo. Respetan mucho al anciano y éstos son exactos en la relación de acontecimientos del pasado.

Pero, qué ocurre en las culturas orales con el tiempo histórico entre la memoria reciente y el pasado mítico de los orígenes, en ese tiempo en el que encuentran su lugar, por ejemplo, la llegada de los españoles o la introducción del caballo. Entre uno y otro tipo de memoria, se abre un abismo que los etnólogos de la comunicación conocen como floating gap. Las genealogías, los relatos genealógicos, son precisamente un puente que sirve para unir los dos extremos de este abismo que se abre entre la memoria comunicativa cotidiana y la memoria cultural. Este es, sin duda, un tema que merecería un análisis que le haga justicia, pero que aquí, lamentablemente, no podemos tratar para no salirnos del cauce fijado.

Entender el valor social de la palabra hablada en la sociedad indígena nos puede mostrar en su envés los valores sociales y culturales que la introducción de un medio más efectivo y fácilmente manipulable como la escritura viene a traslocar. Ya que todos estos relatos que justifican el orden del mundo y hasta el sentido de cada acción cotidiana, no cuentan con ningún otro soporte material que la memoria de los sujetos; la reproducción y recreación de las tradiciones deviene tarea de todo individuo de una comunidad:

Analphabetische, also orale Tradierung der Kultur bedeutet, daß alle, die sprechen können, auch die Möglichkeit haben, auf die Tradition einzuwirken. Schriftliche Tradierung dagegen bedeutet, daß der Zugang zur und die Einflußnahme auf die Kultur von einer besonderen Ausbildung abhängt, die von europäisch geformten Spezialisten, den Lehrern, vermittelt wird. An die Stelle der spontanen Teilnahme aller Dorfbewohner an der gemeinsam erarbeiteten Kultur tritt die Belehrung durch den schriftgelehrten Lehrer. ${ }^{14}$

\footnotetext{
${ }^{14}$ Münzel 1978: 11s. Traducción: “Tradición analfabeta, es decir, oral, de la cultura significa que cualquier persona que puede hablar, tienen la oportunidad de influir sobre la tradición. Tradición escrita por el contrario significa que el acceso y la influencia sobre la cultura depende de una determinada formación que es transmitida por especialistas formados en Europea, los maestros. En el lugar de la participación espontánea de todos los pobladores en una cultura desarrollada conjuntamente, se presenta la instrucción
} 
La escritura viene, pues, a enajenar elementos que son patrimonio común de todos los miembros de una comunidad como la memoria depositándola en manos de "peritos" poseedores de la habilidad de la lecto-escritura. No es otra la operación de Mansilla cuando niega a los Ranqueles la facultad de una memoria cultural para instalar en su lugar la escritura:

Vds. no saben nada, porque no saben leer; porque no tienen libros. Vds. no saben más de lo que les han oído á su padre ó á su abuelo. Yo sé muchas cosas que han pasado ántes. (Cap. LIV)

\section{Escritura y conocimiento}

En las cartas escritas en Leubucó y Poitagüe guardadas en el convento franciscano de Río Cuarto, asoman a cada paso rastros de la oralidad. En su manejo deficiente de los códigos de la escritura (ortografía, sintaxis, aspectos discursivos y genéricos, etc.), los escribas de las mismas bien pueden considerarse como autores "semicultos" (1994). Un ejemplo de "impericia" de tipo sintáctico en la escritura de las cartas es la expresión me han dicho que decir algunos Jefes (D 893) que muestra una posible participación plural en el momento del planeamiento textual de la carta. La tarea siguiente, la tarea de composición textual a cargo de los lenguaraces no era en absoluto sencilla como puede parecer en un primer momento, ya que requería de estos individuos bilingües, junto a la traducción propiamente dicha, de un alto grado de competencia escritural para dar forma a un texto con éxito. El escriba, a la par que borraba su propia participación en el lugar enunciativo, colocaba las palabras en discurso directo en el lugar enunciativo del cacique que "dicta"; el lenguaraz debía en ocasiones hacer un uso apropiado del discurso indirecto al transformar en enunciación singular un texto producido en planeamiento plural como se infiere del ejemplo. Por supuesto la tarea no habría sido tan complicada si el cacique realmente "dictara", pero en no pocos casos el cacique sólo ordena un determinado contenido en lengua mapuche que el lenguaraz debe traducir y ordenar en un mensaje en castellano coherente y ajustado a las normas del género epistolar.

Es decir que el lenguaraz, a la par de la competencia idiomática necesaria, debía poseer una cierta competencia expresiva para comunicarse mediante el tipo textual epistolar. Esta competencia se aprecia claramente en el empleo de fórmulas estandarizadas como los encabezados de saludo y la despedida que seguían patrones relativamente fijos, usados muchas veces en la copiosa correspondencia intercambiada en la frontera, por lo que el escriba sólo debía limitarse a repetir las fórmulas apropiadas según esquemas aprendidos; pero cuando se trataba de la formulación de la intención comunicativa concreta de cada carta, de plasmar por escrito un contenido inédito para decirlo de manera sencilla, debía entonces improvisar según sus propios conocimientos idiomáticos dando lugar con frecuencia a repeticiones y expresiones donde se filtra lo coloquial y donde las dificultades del paso del medio oral al escrito se hacen patentes. Vacilaciones de este tipo en el discurso indirecto y repeticiones de contenido se pueden apreciar en grandes cantidades en la carta del cacique araucano Manuel Namuncurá (D 832):

Esta tiene por conclucion de que Ud se inponga de todo lo que contiene y pase a conocimiento del Essem $^{\circ}$ Reberendo Arzobispo pa que R. E. decirme y comunique que si el Superior Gobierno dela Nacion Argentina quiere traherme la guerra u admitirme los arreglos delos tratados de paz me conteste su R.E. por su escrito y Ud por consiguiente; es cuanto espero tener contestacion en ambos dos y seré agradecido siendo la presente remitida por el conducto de la mano de Casique Epumher que espero recibir por dicha parte su contestacion conducida por mano de Epumher.

La situación no difiere en esencia de la descripta por Johannes Kabatek (2005) en textos castellanos del Medioevo en el caso de formas lingüísticas que no se dejan reducir a fórmulas, sino que requieren del recurso a la oralidad para ser expresadas:

por maestros poseedores del conocimiento de la escritura". 
(...) der Schreiber kennt ein bestimmtes Formelinventar und bestimmte konkrete Texte; aus diesen übernimmt er gewisse Passagen, während er bei neu zu verschriftenden Sachverhalten auf die Übertragung des Gesprochenen ins schriftliche Medium zurückgreifen muss. ${ }^{15}$

Pero nuestra intención aquí no es tanto mostrar la complejidad de la puesta en práctica de las habilidades lecto-escriturales de intérpretes y escribas sino más bien resaltar la importancia social alcanzada por amanuences y lenguaraces como un dato que nos muestra el carácter profundo de las transformaciones culturales que la escritura lleva consigo al ser introducida en la sociedad indígena ${ }^{16}$. La mayor relevancia social de las personas poseedoras de los conocimientos necesarios para esta tarea es indicio de la creciente necesidad de una interpretación exacta de la letra escrita en la sociedad indígena.

Otro indicio notorio de estas transformaciones culturales es la existencia de archivos en las tolderías ranqueles, como testimonia Lucio V. Mansilla cuando relata sobre el archivo de Mariano Rosas, y en otros grupo indígenas como los salineros, como lo muestra Guillermo Durán (2006), quien analiza el contenido del archivo enterrado del cacique Namuncurá conservado por Estanislao Zeballos. La práctica archivista en las tolderías, en consonancia con el tenor "diplomático" de los documentos conservados, es otro aspecto del grado de penetración de la escritura en una sociedad oral como la araucana, ya que, en coincidencia con lo que señala Jack Goody (1990) sobre la conservación de documentos en sociedades de la antigüedad y del África colonial, se conservaron mayoritariamente textos que hacen a las relaciones diplomáticas entre "naciones". Que se conserven sobre todo documentos de índole diplomática y comercial internacional, en principio sólo prueba que éste tipo de documentos se guardaba mejor y por partida doble, ya que, dada su importancia se conservaban más cuidadosamente y se creaban copias para ambas partes, como ocurrió con los numerosos "tratados de paces", lográndose así la conservación de los mismos en muchos más casos que con documentos sobre asuntos domésticos que circularían en copia única. Ahora bien, se puede pensar también que, por lógica, los documentos de un intercambio diplomático entre una nación con escritura y otra oral, son desde la perspectiva de la cultura oral necesariamente primarios. De no mediar un cambio cultural considerable, podemos partir de la base de que una sociedad de tradición oral no necesita para su comunicación interna de más tipos comunicativos que los que han funcionado tradicionalmente. Tipos que, vale recodar, en estos grupos de la etnia araucana eran sumamente complejos y estaban integrados dentro de un sistema con claras jerarquías. La escritura se introduce en una sociedad de cuño oral, pues, a través de las relaciones exteriores con otras sociedades o culturas poseedoras de escritura, antes de alcanzar la esfera doméstica y los asuntos administrativos o comerciales internos (Jack Goody 1990: 172ss.). En este momento se puede hablar de una "restricted literacy", atendiendo además al hecho de que la escritura asume funciones específicas y se desenvuelve en una lengua extranjera (Goody/Watt 1987). Mediante acuerdos o tratados entre dos naciones se regula el intercambio positivo de personas y mercaderías, y a la inversa, se prescriben los elementos que, en caso de su violación, pueden conducir a conflictos, represalias y guerras; en las cartas diplomáticas entre "cristianos" y ranqueles sobre todo se informa y se argumenta en el marco de la negociación de los tratados, aunque también se amenaza de forma más o menos directa. El carácter regulador de prácticas y actos concretos de textos como los tratados de paz hace que una interpretación exacta de lo que regula la letra del acuerdo gane cada vez mayor importancia.

Es decir, en la escritura como práctica se escenifican múltiples elementos que conciernen al funcionamiento de una cultura, más allá de la ventaja práctica universal que ofrece la escritura de permitir comunicarse con exactitud o de librarse de la necesidad de depositar confianza en la

15 Johannes Kabatek 2005: 199. Traducción: “(...) el escriba conoce cierto inventario de formulas y determinados textos concretos de los que toma ciertos pasajes, mientras que los nuevos contenidos que debe transmitir deben ser tomados de la oralidad y tranferidos al medio escrito".

${ }^{16}$ Véase Goody y Watt (1987), Messick (1983: 43ss.). 
memoria, cuando no en la buena fe de un intermediario que transmite el mensaje oralmente; al contrario, con el texto, con su permanencia material, se cuenta con algo a lo que es posible remitirse una y otra vez para juzgar si una práctica es correcta, apropiada o legítima, si una respuesta lingüística que se da es la esperada. El soporte material del texto, el papel, permite además la práctica archivista siguiendo criterios clasificatorios que vienen dados por el contenido y la índole de un texto. La definición de estos criterios está en directa relación con la constitución y afianzamiento de géneros discursivos particulares y, más allá, de universos de discurso.

Es así como la escritura, esta práctica destinada en principio a permitir la comunicación entre dos personas salvando el tiempo y la distancia que la ausencia de contacto supone, siendo una práctica cotidiana y constitutiva de una cultura, se introduce en la segunda sociedad pasando a integrarse paulatinamente en la misma y a condicionarla interiormente. El archivo de notas oficiales, cartas, borradores, periódicos de Mariano Rosas, descrito por Mansilla, nos muestra hasta qué punto la escritura comenzaba a tomar el lugar del sujeto en el ejercicio memorístico en la sociedad de los ranqueles; la práctica archivista, pues, compite con mayores posibilidades de éxito que los archivos vivos de la memoria de los ancianos de la tribu. Nótese que Mariano Rosas, aún sin saber leer, conoce perfectamente el contenido de cada papel y está en condiciones de señalar un fragmento de un artículo que había sido manoseado muchas veces, donde se encuentra la información que desea discutir:

Y esto diciendo, se levantó, entró en el toldo y volvió trayendo un cajón de pino, con tapa corrediza.

Lo abrió y sacó de él una porción de bolsas de zaraza con jareta.

Era su archivo.

Cada bolsita contenía notas oficiales, cartas, borradores, periódicos.

El conocía cada papel perfectamente.

Podía apuntar con el dedo el párrafo á que queria referirse.

Revolvió su archivo, tomó una bolsita, descorrió la jareta y sacó de ella un impreso muy doblado y arrugado, revelando que había sido manoseado muchas veces.

Era «La Tribuna» de Buenos Aires.

En ella había marcado un artículo sobre el gran ferrocarril interoceánico.

Me lo indicó, diciéndome:

- Lea, hermano.

Conocia el artículo y le dije:

- Ya sé, hermano, de lo que trata.

- $\quad$ Y entónces por qué no es franco?

- Cómo franco?

- $\quad \mathrm{Si}$, usted no me ha dicho que nos quieren comprar las tierras para que pase por el Cuero un ferro-carril.

Aquí me ví summamente embarazado.

Hubiera previsto todo, ménos un argumento como el que se me acababa de hacer. (Cap. XL)

Resumiendo, la actividad archivista del cacique trae consigo toda una serie de consecuencias directas e indirectas que aproximan la administración interna de esta sociedad tribal al funcionamiento más complejo de las sociedades con escritura y, más allá, con una organización burocrática estatal ${ }^{17}$. Disposiciones de carácter legal, como los tratados de paz se asientan por escrito y se conservan en archivos que, dado el rango y función del cacique, exceden la esfera privada provocando consecuencias en el espacio público de la sociedad indígena. Al regular una serie de actos individuales o colectivos posteriores, los documentos revisten carácter legal, lo cual lleva a poner mayor valor en la exactitud de la interpretación de lo que está para "cumplir" y para "hacer cumplir"" . Los textos escritos aspiran a una mayor durabilidad pudiendo ser

\footnotetext{
${ }^{17}$ Véase sobre la influencia de la escritura en la organización estatal Jack Goody 1990: 152ss.

${ }^{18} \mathrm{Al}$ mismo tiempo, en la escritura se escenifican relaciones de poder que no son tan relevantes en nuestra perspectiva: “(...) el dominio de la escritura resultó un elemento central en el desarrollo de la política
} 
consultados cada vez que se desee confirmar o modificar algún punto, o bien, repetirlo, transformándolo además en modelo de prácticas textuales posteriores. La repetición de formas y contenidos está precisamente en la base de la constitución y desarrollo de las tradiciones discursivas.

Como hemos visto, la memoria cumple en las sociedades orales la tarea de selección de lo recordable, eliminando al mismo tiempo aquello que resulta superfluo. En la memoria de archivo todo se conserva, quedando el sujeto ante el problema de seleccionar y jerarquizar los elementos de un conjunto de informaciones o conocimientos a veces incompatibles entre sí. La constitución de "universos discursivos" es la solución que se ofrece para establecer jerarquizaciones en este conjunto heterogéneo, otorgando distintos valores de verdad a los diferentes textos.

En una carta datada el 4 de julio de 1878 y que se encuentra citada en la Historia de los indios ranqueles de J. Fernández C. (1998: 207s.), el cacique Epumer reclama al gobierno argentino una escritura firmada de propiedad sobre sus propios territorios:

También suplico a V.S., sobre los terrenos que no salgan más los fortines al Sud. V.S. sabe que territorios son nuestros y que para mi respecto, que el Excmo. Sr. Presidente y V.S. me den una escritura firmada para que de esa manera sean los terrenos respetados por la Nación.

El gesto del cacique reclamando el reconocimiento escrito del gobierno argentino sobre territorios que ocupaban desde generaciones nos muestra el sentimiento de derrota que ya adoptaba formas concretas en la otrora orgullosa cultura araucana. Se llegaría a firmar todavía un último tratado de paz de efímera duración a fines de julio de 1878. A principios de noviembre comienzan sin embargo los movimientos militares de la llamada Conquista del Desierto. La campaña militar barrerá los territorios indígenas de la pampa y el norte patagónico avanzando desde distintos puntos. El cacique Epumer resultará apresado y enviado prisionero a la isla Martín García y Baigorrita terminará muerto en su intento de fuga buscando alcanzar un paso a Chile por la cordillera de los Andes. Tras la derrota, pocos indígenas quedarán en sus antiguos territorios, siendo la mayoría enviados a trabajar en la zafra tucumana, la marina o el servicio doméstico en las ciudades de Mendoza y Buenos Aires, en el caso de las mujeres y los niños.

\section{A manera de conclusión}

La publicación en las últimas décadas de nuevas fuentes abren a la historiografía lingüística variadas posibilidades con las que los investigadores de la lengua sólo podían soñar en el pasado. En estas páginas adoptamos lo que Coseriu define como una perspectiva de etnografía lingüística (Coseriu 1981), al concentrarnos en los cambios sociales y culturales que un elemento como la escritura trae aparejados con su introducción en una sociedad y su incorporación como elemento central de nuevas elites. Dos de los principales elementos afectados son la memoria cultural y el estatus social del conocimiento y sus modos de conservación y circulación, y ésto no sólo visto desde la perspectiva de los cristianos como se apunta en la cita más arriba, en la que el coronel Mansilla quita legitimidad al saber y la memoria de los indígenas por desconocer la escritura, sino también visto desde la perspectiva indígena misma, como lo demuestra la incorporación de la práctica archivística en las tolderías y se deja inferir del permanente recurso a la letra de los tratados de paz en sus cartas como instancia legal normativa y modelo lingüístico para la introducción de nuevas tradiciones discursivas.

interétnica, dado que la sociedad que poseyera el control de lo plasmado en las actas de los tratados, además de imponer su posición sobre lo acordado, podría crear su propia versión de lo pactado“ (Graciana Pérez Zavala 2005: 2). 


\section{Bibliografía}

ÁLVAREZ CASTRO, Natalia (2006): "Consideraciones metalingüísticas sobre el entorno 'universo de discurso' de Eugenio Coseriu”. En: González Ruiz, Ramón/ Casado Velarde, Manuel/ Esparza Torres, Miguel (eds.): Discurso, lengua y metalenguaje. Balance y perspectivas - Buske - Hamburg - (págs. 21-35).

ASSMANN, Jan (2005): Das kulturelle Gedächtnis. Schrift, Erinnerung und politische Identität in frühen Hochkulturen - Beck - München.

AVENDAÑO, Santiago (2004): Memorias del ex cautivo Santiago Avendaño (1834-1874). Recopilación de P. Meinrado Hux - El Elefante Blanco - Buenos Aires.

BECHIS, Martha (2008): Piezas de etnohistoria del sur sudamericano - C.S.I.C. - Madrid:

BERNAL, Irma (1997): Rosas y los indios - Ediciones Búsqueda de Ayllú - Concepción del Uruguay, Entre Ríos.

BÜHLER, Karl (21965): Sprachtheorie. Die Darstellungsfunktion der Sprache - Gustav Fischer Verlag - Stuttgart ( ${ }^{1} 1934$, Jena). [Traducción española de Julian Marías (1950): Teoría del lenguaje - Revista de Occidente - Madrid].

COSERIU, Eugenio (1955/56): "Determinación y entorno. Dos problemas de una lingüística del hablar”. Romanistisches Jahrbuch 7 (págs. 29-54) [reedición en: id. (1967): Teoría del lenguaje y lingüistica general. Cinco estudios - Gredos - Madrid (págs. 282-323)].

COSERIU, Eugenio (1981): "La socio- y la etnolingüística. Sus fundamentos y sus tareas". Anuario de Letras XIX - México (págs. 5-29).

DURÁN, Juan Guillermo (2006): Namuncurá y Zeballos: El archivo del cacicazgo de Salinas Grandes (1870-1880) - Bouquet - Buenos Aires.

FERNÁNDEZ C., Jorge (1998): Historia de los indios ranqueles. Orígenes, elevación y caída del cacicazgo ranquelino en la pampa central (Siglos XVIII y XIX) Instituto Nacional de Antropología y Pensamiento Latinoamericano - Buenos Aires.

GREGORIO-CERNADAS, Maximiliano (1998): “Crítica y uso de las fuentes históricas relativas a la diplomacia indígena en la pampa durante el siglo XIX". Memoria Americana 7 (págs. 61-89).

GOODY, Jack/ WATT, Ian (1987): "Konsequenzen der Literalität”. En: Goody, Jack (ed.): Literalität in traditionalen Gesellschaften - Suhrkamp - Frankfurt am Main (págs. 45104) [( $\left.{ }^{1} 1968\right):$ "The consequences of literacy", in: Literacy in Traditional Societies Cambridge University Press (págs. 27-68)].

GOODY, Jack (1990): Die Logik der Schrift und die Organisation von Gesellschaft - Suhrkamp - Frankfurt am Main.

KABATEK, Johannes (2005): Die Bolognesische Renaissance und der Ausbau romanischer Sprachen. Juristische Diskurstraditionen und Sprachentwicklung in Südfrankreich und Spanien im 12. und 13. Jahrhundert - Max Niemeyer Verlag - Tübingen.

KORNFELD, Laura/ KUGUEL, Inés (1995): "Dos proyectos de integración del indígena a la nación argentina: la "Gramática y diccionario de la lengua pampa" de Juan Manuel de Rosas (1825) y el "Manual de la lengua pampa" de Federico Barbará (1879)". Letterature d'America 15/59 (págs. 149-180).

LEVAGGI, Abelardo (2000): Paz en la frontera. Historia de las relaciones diplomáticas con las 
comunidades indigenas en Argentina (siglos XVI-XIX) - Dunken - Buenos Aires.

LÜDTKE, Jens (2007): "Las corrientes de la hispanización lingüística de Hispanoamérica". En: Actas del XV Congreso de la Asociación Internacional de Hispanistas: "Las dos orillas" - F.C.E./ El Colegio de México - México (págs.123-147).

MANSILLA, Lucio Victorio (1877): Una escursión á los indios ranqueles - 2 vols. - F. A. Brockhaus - Leipzig (Colección de Autores Españoles XXXIX).

MARTÍNEZ SARASOLA, Carlos (1992): Nuestros paisanos los indios. Vida, historia y destino de las comunidades indigenas en la Argentina - Emecé - Buenos Aires.

MESSICK, Brinkley (1983): "Legal documents and the concept of 'restricted literacy' in a traditional society". Wagner, Daniel (ed.): Literacy and ethnicity - International Journal of the Sociology of Language 42 (págs. 41-52).

MÜNZEL, Mark (1978): "Indianische Mythen und europäischer Indigenismus. Zur Frage der oralen indianischen Literatur in Lateinamerika". Iberoamericana 2 (págs. 3-17).

OESTERREICHER, Wulf (1994): „El español en textos escritos por semicultos. Competencia escrita de impronta oral en la historiografía indiana”. In: Lüdtke, Jens (ed.): El español de América en el siglo XVI - Vervuert - Frankfurt am Main (págs. 155-190).

PÁVEZ OJEDA, Jorge (2008): Cartas mapuche: Siglo XIX - Ocho Libros/CoLibris - Santiago de Chile.

PÉREZ ZAVALA, Graciana (2005): “Oralidad y escritura: los tratados de paz entre el Estado argentino y las tribus ranqueles". TEFROS - Taller de etnohistoria de la frontera sur 3, 1 en http://www.unrc.edu.ar/publicar/tefros/revista/v3n1p05/completos/oralidad.pdf

RATTO, Silvia (2007): Indios y cristianos. Entre la guerra y la paz en las fronteras Sudamericana - Buenos Aires.

SALOMÓN TARQUINI, Celia Claudia (2006): "Santiago Avendaño: «El niño que hablaba con el papel»". En: Mandrini, Raúl (ed.): Vivir entre dos mundos. Las fronteras del sur de la Argentina. Siglos XVIII y XIX - Taurus - Buenos Aires (págs. 119-136).

TAMAGNINI, Marcela ( $\left.{ }^{1} 1995\right)$ : Cartas de frontera. Los documentos del conflicto interétnico Universidad Nacional de Río Cuarto - Río Cuarto (2011).

VEZUB, Julio Esteban (2006): "El gobernador indígena de las Manzanas. Don Valentín Sayhueque". En: Madrini, Raúl (ed.): Vivir entre dos mundos. Las fronteras del sur de la Argentina. Siglos XVIII y XIX - Taurus - Buenos Aires (págs. 289-318).

WEBER, David J. (2005): Bárbaros: Spaniards and Their Savages in the Age of Enlightenment - Yale University Press - New Haven/ London. 